\title{
O Geomarketing como Instrumento para a Pesquisa de Mercado: estudo de caso do Supermercado Sacolão Big Dog em Londrina-PR
}

\author{
The Geomarketing as an Instrument for Market Research: case of study in \\ Supermarket Greengrocer Big Dog in Londrina-PR
}
El Geomarketing como Instrumento para la Investigación de Mercado: estudio del caso del Supermercado Sacolón Big Dog en Londrina-PR

\author{
Flávio Henrique Navarro Hashimoto ${ }^{1}$ \\ Osvaldo Coelho Pereira Neto ${ }^{2}$
}

\begin{abstract}
RESUMO: O presente artigo visa apresentar os resultados obtidos por meio de uma pesquisa de mercado realizado no Supermercado Sacolão Big Dog, localizado em Londrina-PR, utilizando o geomarketing como técnica de estudo. Para o desenvolvimento da pesquisa foram aplicadas 200 entrevistas com consumidores que estavam consumindo in loco no supermercado. Após isso, foi feito a tabulação desses dados e mapeadas a localização desses entrevistados para verificar a situação mercadológica da empresa. Constatou-se que o Supermercado Sacolão Big Dog, mesmo sendo uma empresa considerada pequena, apresenta uma representatividade espacial (no ramo supermercadista) considerável no município de Londrina-PR.
\end{abstract}

PALAVRAS-CHAVE: Geomarketing. Geoprocessamento. Pesquisa de mercado.

ABSTRAC: This article aims to present results by means of a market research carried out at the Big Dog Supermarket, located in Londrina-PR, using geomarketing as a study technique. For the development of the research, 200 interviews were applied on consumers who were consuming in loco in the supermarket. After that, a survey of data and mappings of a professional meeting was done to verify a company's marketing situation. It was found that the Supermarket Greengrocer Big Dog was a small company, presents a considerable spatial representation (in the supermarket branch) in the city of Londrina-PR.

KEY WORDS: Geomarketing. Geoprocessing. Market research.

RESUMEN: El presente artículo tiene por objeto presentar resultados a través de una encuesta de mercado realizada en el Supermercado Sacolón Big Dog, ubicado en Londrina-PR, utilizando el geomarketing como técnica de estudio. Para el desarrollo de la investigación se aplicaron 200 entrevistas en consumidores que estaban consumiendo in loco en el supermercado. Después de eso, se hizo un levantamiento de datos y mapeamientos de una reunión de profesionales para verificar una situación mercadológica de la empresa. Se constató que el Supermercado Sacolón Big Dog, fue una empresa constituida pequeña, presenta una representatividad espacial (en el sector supermercadista) considerable en el municipio de Londrina-PR.

PALABRAS-CLAVE: Geomarketing. Geoprocessamiento. Investigación de mercado.

\footnotetext{
${ }^{1}$ Universidade Estadual de Londrina. Rodovia Celso Garcia Cid - PR 445 - Km 380 Cx. Postal 10.011 - Campus Universitário, PR, 86057-970. flaviohnavarro@yahoo.com.

${ }^{2}$ Universidade Estadual de Londrina. Rodovia Celso Garcia Cid - PR 445 - Km 380 Cx. Postal 10.011 - Campus Universitário, PR, 86057-970. coelho@uel.br.
} 


\section{INTRODUÇÃO}

Um estudo que visa verificar a situação mercadológica de uma empresa possibilita aos responsáveis terem o conhecimento do estado em que se encontra ou do setor que atua(rá). Esse fator é necessário para qualquer porte de empresa, principalmente para os micro e pequena, uma vez que a sua sobrevivência é mais dificultosa em relação às de porte grande, já que não possuem uma estrutura que as auxiliem no seu desenvolvimento.

Partindo desse pressuposto, a presente pesquisa buscou utilizar o geomarketing como instrumento para verificar a situação mercadológica de uma pequena empresa. Realizou-se um estudo de caso de geomarketing no Supermercado Sacolão Big Dog para verificar a situação mercadológica desta empresa de pequeno porte que atua em um setor competitivo, que é o setor supermercadista. A empresa está localizada no município de Londrina, Estado do Paraná, e o "Big Dog", como popularmente conhecido, é uma empresa de porte pequeno, contudo a empresa contém uma representatividade local, a priori, relevante, mesmo estando instalada em uma região que contém ali presentes concorrentes de grande porte do setor supermercadista.

Por meio do geomarketing é possível espacializar a situação da empresa ou do setor, possibilitando auxílio na tomada de decisões. Com o geomarketing foi possível identificar o raio de ação do Supermercado Sacolão Big Dog, onde se localiza a sua clientela e o que pensam os seus consumidores sobre a estrutura do serviço prestado. Isso permitiu que o gestor da empresa pudesse ter uma visão sobre a situação de mercado da empresa e assim tomar decisões com menos riscos e mais preciso.

Por fim, o estudo foi elaborado de uma forma que pudesse discutir sobre como o geomarketing consegue espacializar a situação mercadológica de uma empresa de pequeno porte, como o caso do Supermercado Sacolão Big Dog. Além do mais, foi visado também discutir uma temática ligada ao Geoprocessamento e a Geografia do Comércio, mas que não se tem muitas informações de pesquisadores da área da Ciência Geográfica. Além disso, a pesquisa visou também contribuir para uma temática que pode ser um novo espaço de trabalho para os geógrafos.

\section{GEOMARKETING: FRUTO DA INTEGRAÇÃO DE GEOGRAFIA COM O MARKETING}

O geomarketing, segundo Furlan (2011, p. 99), “[...] pode apresentar-se como uma tendência atual, novidade ou inovação". Os estudos relacionados ao geomarketing podem 
também serem denominados como: Geografia do Marketing, Geografia do Mercado e Marketing Geográfico. Marketing Territorial é outra forma de designar estudos de geomarketing (YRIGOYEN, 2003). Contudo, a nomenclatura a ser utilizada neste trabalho será geomarketing.

O geomarketing surgiu da necessidade do marketing em buscar soluções para as empresas. "O geomarketing responde a um grande número de questões que surgem das problemáticas de marketing" (CAVION, 2008, p. 11). A busca de conhecer o raio de ação do público-alvo, por exemplo, faz com que o geomarketing ganhe uma função importante, já que possibilita ao marketing obter essa informação como um fator diferencial na ação de decisão. O geomarketing, de acordo com Seabra (2014, p. 24), tem como objetivo ter uma abordagem geográfica sobre a situação da empresa:

[...] o marketing geográfico vem trazer uma nova dimensão, a dimensão espacial, ao estudo e à análise dos fenômenos socioeconômicos, comportamentais, demográficos e estatísticos de um determinado mercado, fenômenos estes que sempre estiveram presentes nos estudos e estratégias de marketing.

Conforme apontam Machado, Francisco e Ribeiro (2006, p. 86), o geomarketing "[...] é um conjunto de metodologias e ferramentas que objetivam analisar componentes, ou atributos locais ou regionais que permitam a implementação de recurso apropriados para atender/aumentar/estimular a demanda local". Para os autores, o geomarketing tem como função descobrir qual é a melhor forma de implantar um formato da publicidade da empresa que atenda o público-alvo, utilizando técnicas ligadas a Geografia Econômica e Estatística.

Para Latour e Floc'h, segundo aponta Yrigoyen (2003, p. 7), o geomarketing é um sistema de dados integrados em softwares de SIG (Sistema de Informação Geográfica) e utiliza os métodos estatísticos e representações gráficas para fornecer as informações: "[...] un sistema integrado por datos, programas informáticos de tratamiento, métodos estadísticos y representaciones gráficas destinado a producir una información útil para la toma de decisiones, a través de instrumentos que combinan la cartografía digital, gráficos y tablas".

Já para Canova (2007, p. 62), “[...] o geomarketing [...] é um ramo de aplicação do geoprocessamento que possibilita a organização e a manipulação de informações referentes a clientes e pesquisas, a partir de um ponto de vista geográfico". É através dessa área que é possível analisar a distribuição dos consumidores ou do público-alvo em mapas, além de também observar a atuação dos concorrentes.

Para conseguir esse objetivo o geomarketing busca espacializar a distribuição de clientes e dos grupos-alvos em mapas. Com os dados espacializados é possível obter informações mais precisas para a empresa (DASCALU; ALBULESCU, 2014). 
Em momentos de crises, conforme aponta Furlan (2011, p. 100), “[...] o geomarketing tende a se afirmar cada vez mais [...] quando, para as empresas, se torna, então, vital aprimorar técnicas de captação de clientes, estratégias de venda e propaganda direcionada, entre outros". Na busca de maximizar os lucros e de minimizar os custos, as empresas buscam caminhos nesses momentos complicados, e, devido a esse fator, o geomarketing ganha destaque e se torna uma das áreas no fornecimento de informações que podem impactar decisões importantíssimas do rumo da empresa.

De acordo com Furlan (2011, p. 99), "[...] um exemplo (de geomarketing) seriam os mapas com alfinetes para a localização de uma determinada loja com cores vermelhas, as concorrentes com cores verdes e assim sucessivamente". Outro exemplo são os mapas com alfinetes interligados por barbantes que visa verificar as distâncias. São várias formas de como realizar um trabalho de geomarketing, desde que o objetivo central desta área seja o mapeamento de interesse de mercado.

O uso de mapas como forma de conhecer a situação mercadológica, segundo Hashimoto (2016), possibilita com que a empresa verifique a sua presença espacial, permitindo assim averiguar quais estratégias são melhores para serem utilizadas.

Além do mais, o geomarketing também pode ser um novo campo de atuação profissional para o geógrafo, uma vez que sua formação acadêmica lhe permite ter uma competência significativa referente aos estudos relacionados ao geomarketing, pois a sua formação the prepara um olhar diferenciado dos dados espaciais, em relação aos outros profissionais.

Por fim, devido à pouca quantidade de estudos sobre geomarketing realizadas por geógrafos, situação essa constatada na busca de estudos para a realização desta pesquisa, se faz necessário a procura pelo desenvolvimento de pesquisas nessa área por parte dos profissionais da Geografia. Este campo é relativamente pouco explorado pelos geógrafos e, devido a isso, se tem a falta de referências deste profissional, tendo-se, então, de buscar material bibliográfico específico de profissionais de outras áreas.

\section{PROCEDIMENTOS METODOLÓGICOS}

Para a realização da presente pesquisa se realizou inicialmente uma entrevista com o responsável pela empresa. Nesse encontro foi apresentado qual era o objetivo deste estudo e se procurou conhecer um pouco da história do supermercado, para assim compreender como se deu a situação mercadológica do Supermercado Sacolão Big Dog.

$\mathrm{Na}$ sequência, após esse primeiro contato e quando se obteve autorização da empresa, foi elaborado e aplicado um questionário em 200 consumidores in loco. A escolha desse número de entrevistados se deve porque foi relatado sobre a média de clientes 
diários, que gira em torno de 2.000 pessoas, fazendo com que se escolhesse $10 \%$ dessa média para serem entrevistados. Essa porcentagem foi definida porque essa quantidade já permitiria ter uma breve compreensão da situação mercadológica da empresa e também ter sido sugerida pelo empresário essa quantidade de entrevistados.

Perguntou-se para os clientes: onde residiam, sua idade, escolaridade e renda familiar. Após essa parte os clientes tiveram que avaliarem algumas características referentes a empresa e da sua prestação de serviço.

Em seguida, se deu a realização do procedimento de tabulação dos dados e o mapeamento da localidade dos entrevistados. Para essa parte da pesquisa se utilizou o software SPRING 5.3, sendo que a base cartográfica shapefile é o de arruamento de Londrina. Esse shapefile foi obtido por meio de download free no portal SIGLON da Prefeitura Municipal de Londrina, através do link "Bacia Hidrográfica - área urbana" (LONDRINA, 2017c).

O SPRING, segundo o (INPE) Instituto Nacional de Pesquisas Espaciais (2017), "[...] é um SIG (Sistema de Informações Geográficas) no estado-da-arte com funções de processamento de imagens, análise espacial, modelagem numérica de terreno e consulta a bancos de dados espaciais". Seus objetivos são: construir um sistema de informações geográficas para aplicações em agricultura, floresta, gestão ambiental, Geografia, Geologia, planejamento urbano e regional; tornar amplamente acessível para a comunidade brasileira um SIG de rápido aprendizado; fornece um ambiente unificado de Geoprocessamento e Sensoriamento Remoto para aplicações urbanas e ambientais; e ser um mecanismo de difusão do conhecimento desenvolvido pelo Instituto Nacional de Pesquisas Espaciais (2017) e seus parceiros, sob forma de novos algoritmos e metodologias. Além desse software, foi também utilizado o Google Earth PRO (2018) para a análise espacial.

Depois dessa etapa foi organizado e a catalogado as referências que poderiam auxiliar na pesquisa. Com essa catalogação, na sequência se deu o fichamento e a escrita do trabalho.

\section{O SUPERMERCADO SACOLÃO BIG DOG COMO ÁREA DE ESTUDO}

O Supermercado Sacolão Big Dog se encontra na Avenida Serra da Esperança, no 1.397, no bairro Jardim Bandeirantes, região Oeste da área urbana de Londrina-PR. O município em que está instalada essa empresa se localiza na Mesorregião Norte Central Paranaense, na Microrregião Geográfica de Londrina e na Região Metropolitana de Londrina, sendo que a população estimada no ano de 2017 foi de 558.439 habitantes pelo IBGE em 2017 no município de Londrina-PR (LONDRINA, 2017a). 
Já o PIB (Produto Interno Bruto) per capita do município era de $\mathrm{R} \$ 32.387,00 \mathrm{em}$ 2015. O responsável por esse valor se deve ao comércio que foi a principal atividade e representou $80 \%$ desse $\mathrm{PIB}$, seguido dos $18 \%$ da indústria e outros $2 \%$ da agropecuária (LONDRINA, 2017b). Na Figura 1 é possível visualizar a localização da única unidade do Supermercado Sacolão Big Dog no software Google Earth PRO.

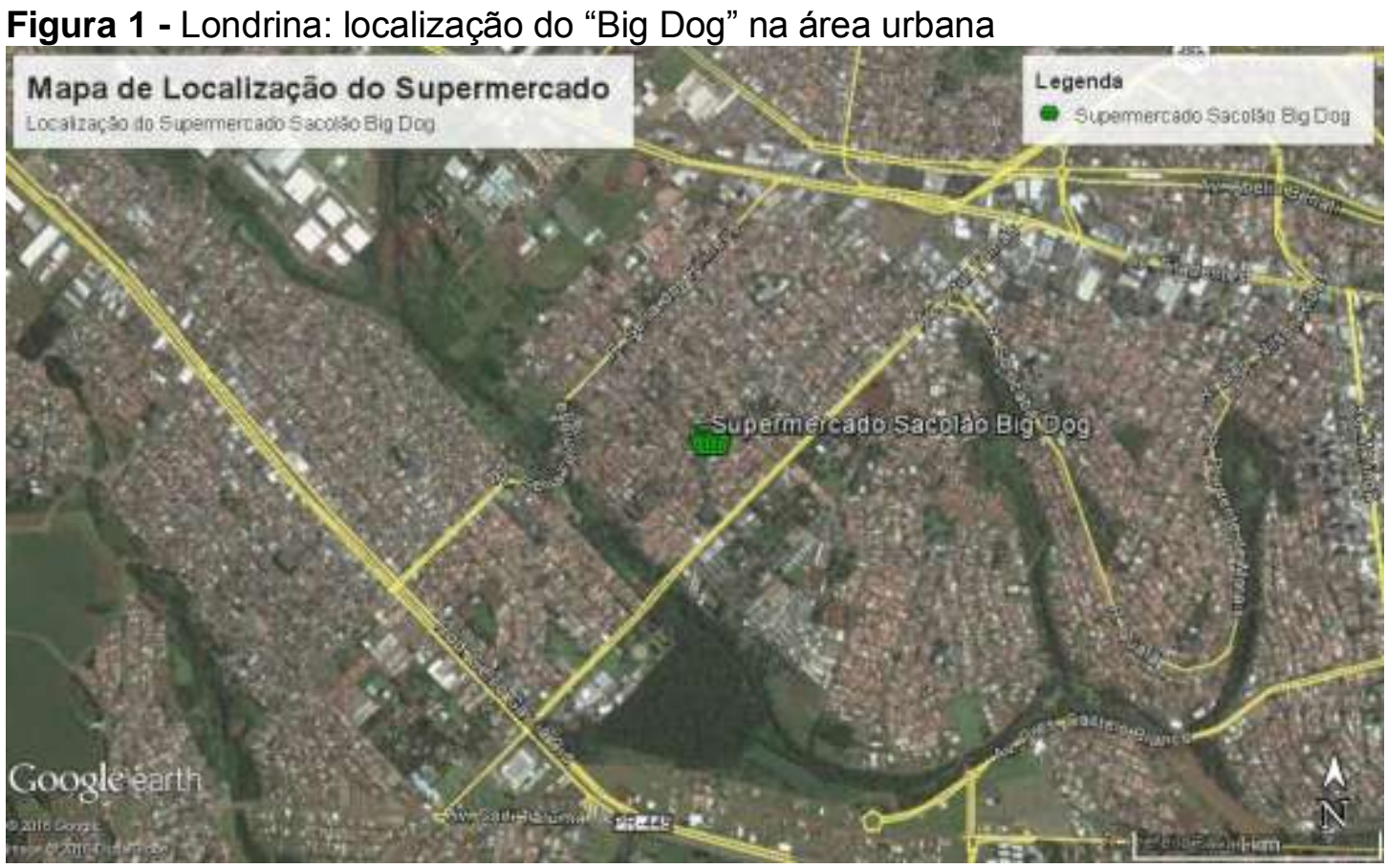

Fonte: Adaptado por Hashimoto de: Google Earth PRO (2016).

O "Big Dog" está localizado numa região de área urbana e situado nas proximidades de vias de acesso rápido - avenidas e rodovias. Além disso, a empresa está próxima da divisa dos municípios de Londrina-PR e Cambé-PR.

A marca "Big Dog" foi fundada em 1996 por meio da parceria dos irmãos Roberto, Jorge e Tamae Shiki. O começo da marca se iniciou como uma lanchonete e depois se expandiu para outros ramos.

No ano de 2005, conforme relatado pelo proprietário do supermercado, visando expandir a marca, os irmãos separam a sociedade e começou a cada um focar apenas uma área específica da marca. Tamae ficou responsável pela Lanchonete Big Dog Lanches, já Jorge ficou com o supermercado e o Roberto abriu a empresa Box Big Dog - um atacado de produtos hortifrutigranjeiros (SUPERMERCADO BIG DOG, 2018). Na Figura 2 é possível visualizar a frente da empresa em 2016 de uma imagem retirada no software Google Earth PRO.

O "Big Dog" é associado à Rede Assurel de Supermercados e é visado auxiliar um grupo de supermercados associados a competirem igualmente no mercado, por meio de 
produtos com qualidade e preço, perante os concorrentes de grande porte (ASSUREL, 2018). Esse modelo de "associativismo" permite aos associados competirem de uma forma menos desigual diante das grandes redes supermercadistas.

Figura 2 - Frente do Supermercado Sacolão Big Dog

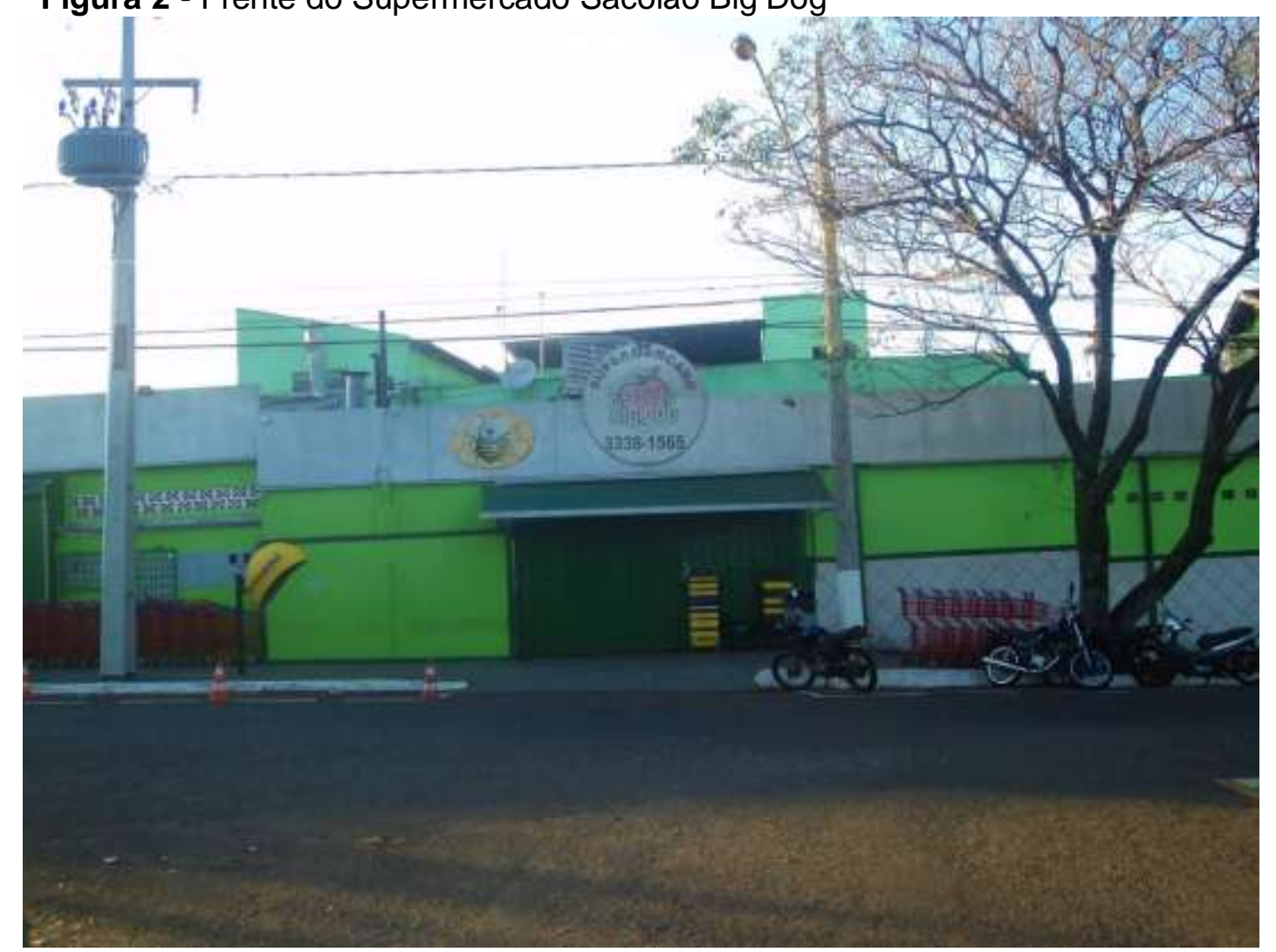

Fonte: Adaptado por Hashimoto de: Google Earth PRO (2016).

As empresas associadas na Rede Assurel são de porte micro e pequeno, fator este que as dificulta competirem de forma mais próximas das grandes redes do setor. Devido a isso, o associativismo se torna um dos caminhos para diminuir essa diferença desproporcional entre as empresas e contribuir para o desenvolvimento delas.

\section{A SITUAÇÃO MERCADOLÓGICA DO SUPERMERCADO SACOLÃO BIG DOG}

Com a realização das 200 entrevistas finalizadas, teve-se na sequência o mapeamento das localizações das residências dos entrevistados (as), além dos concorrentes próximos. Depois de mapeados os dados, foram possíveis então analisar a situação espacial do Supermercado Sacolão Big Dog e averiguar como é a sua presença em seu setor.

De início, na Figura 3, é demonstrada a localização da concorrência do Supermercado Sacolão Big Dog. Foram consideradas dez empresas como concorrentes diretos, não 
estando computados os localizados no município de Cambé/PR e os mercados de porte micro (como as mercearias e os sacolões).

Figura 3 - Localização do Supermercado Sacolão Big Dog e de seus concorrentes próximos em Londrina-PR

\section{SUPERMERCADOS CONCORRENTES}

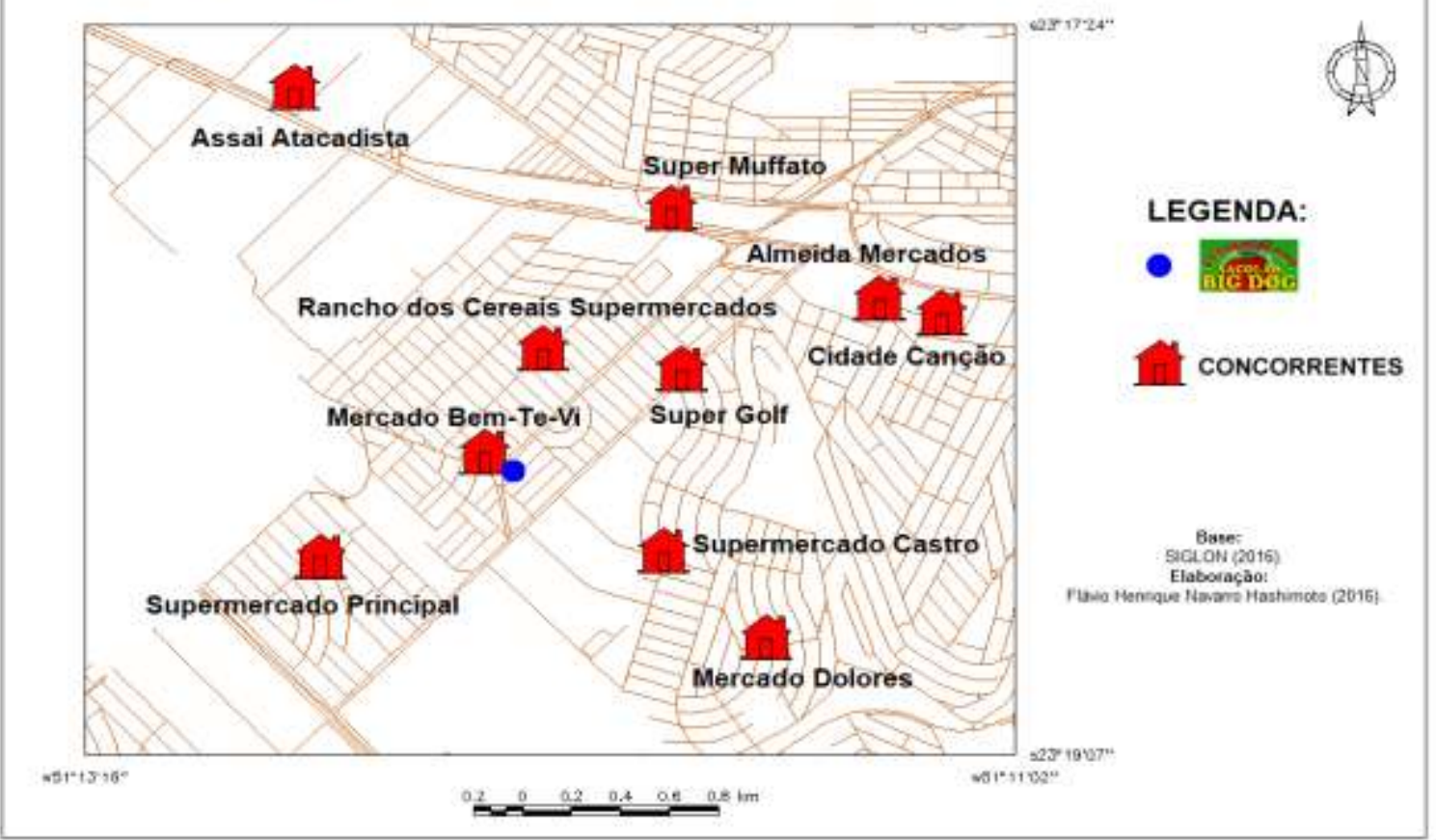

Fonte: Hashimoto (2016).

Consideraram-se os seguintes supermercados concorrentes: Assaí Atacadista; Super Muffato (no dia 28 de setembro o Grupo Muffato inaugurou nessa loja o Max Atacadista, substituindo a sua outra marca, porém durante a catalogação e análise dos dados ainda era o Super Muffato); Almeida Mercados; Cidade Canção; Rancho dos Cereais Supermercados (no final de julho e início de agosto de 2016 o Rancho dos Cereais foi vendido e comprado pelo Supermercado Principal, fazendo com que se tornasse mais uma unidade dessa empresa e, assim como no caso do Super Muffato, a catalogação e análise dos dados foi realizada no período de existência do Rancho dos Cereais Supermercados); Supermercado Principal; Super Golf; Mercado Dolores; Supermercado Castro; e Mercado Bem-Te-Vi. Algumas dessas empresas podem até serem de porte micro, contudo, esses mesmos supermercados apresentam certa representatividade no bairro ou na região, diferentemente de outras micros que foram desconsideradas como concorrentes diretos do Supermercado Sacolão Big Dog.

Logo adiante, na Figura 4, se verifica a localização dos clientes entrevistados próximos da empresa. Neste mapa é possível visualizar uma concentração de clientes que residente 
nas proximidades do Supermercado Sacolão Big Dog. Mesmo com a grande presença de concorrentes, o "Big Dog" tem uma presença significativa, abrangendo ruas nas quais se concentram condomínios fechados e clientes que residem quase ao lado de outros supermercados.

Figura 4 - Localização dos clientes próximos da empresa em Londrina-PR

\section{LOCALIZAÇÃO DOS CLIENTES PRÓXIMOS}

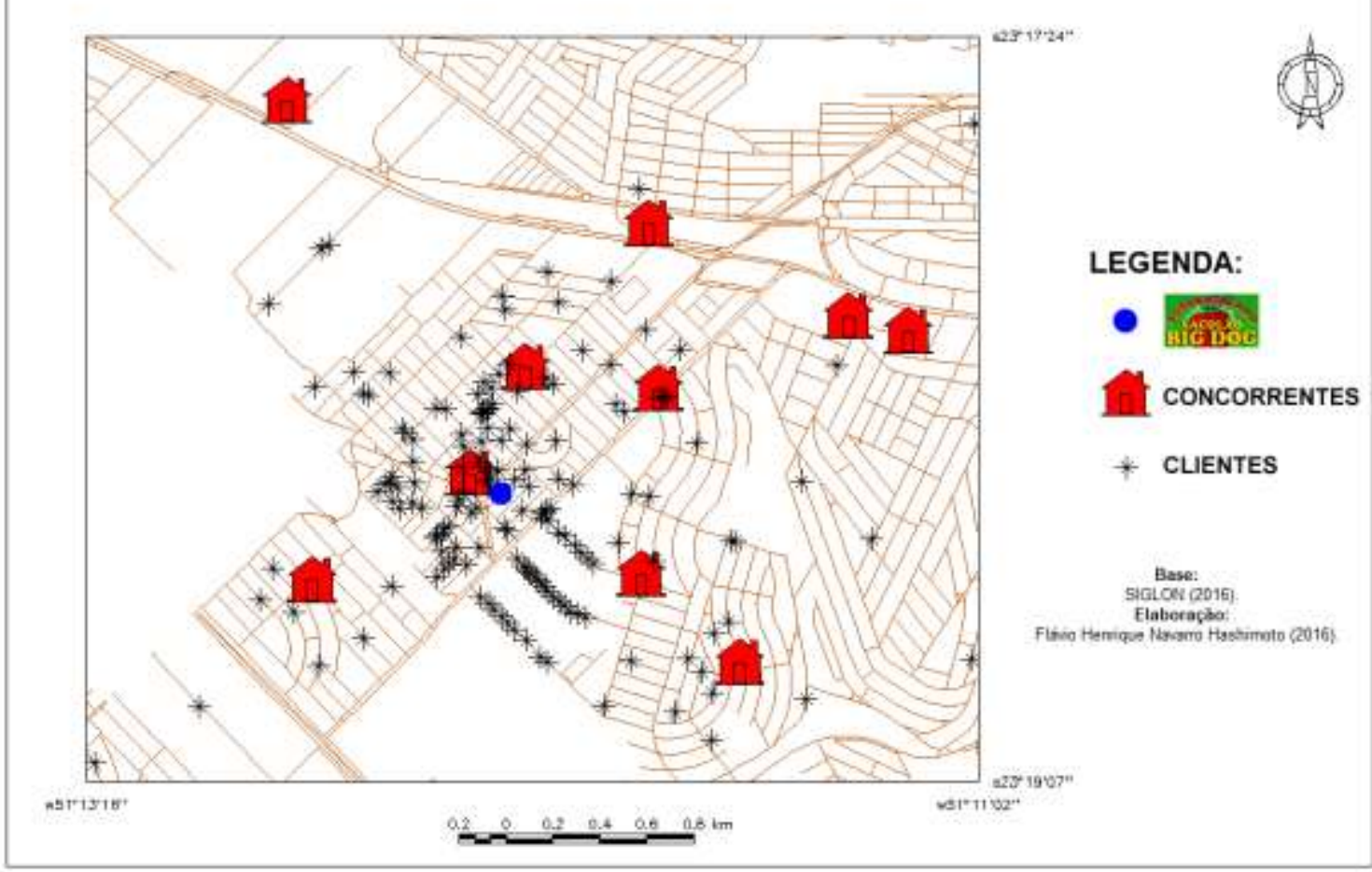

Fonte: Hashimoto (2016).

Em relação dessa concentração de diversos concorrentes próximos, fator este que pode parecer algo que atrapalhe, ou seja, um empecilho, essa situação se torna um fator positivo, segundo relato do proprietário. Com essa proximidade de uma quantidade razoável de concorrentes permite ao "Big Dog" se informar dos preços aplicados pela concorrência e dos tipos de mercadorias e serviços prestados por essas empresas, além saber das novidades do setor.

Já na Figura 5 se observa a localização dos clientes próximos divididos em zonas. No ponto azul é identificada a localização do Supermercado Sacolão Big Dog, e, com isso, se vê uma forte presença de clientes residentes próximos da empresa. Já a representação de cor verde escuro informa uma alta densidade de consumidores do supermercado.

Um pouco mais afastado da empresa, num tom verde médio, verifica-se uma diminuição de sua presença, mas não perde muito a sua representatividade nessas áreas. Logo adiante, no mapa, se visualiza várias baixas densidades de consumidores na cor verde 
claro, consumidores estes que se localizam em áreas um pouco mais afastadas da empresa e só podem obter um acesso fácil através de algum transporte - a pé é possível, no entanto é dificultado pela distância considerável.

Figura 5 - Clientes próximos divididos por zonas

\section{CLIENTES PRÓXIMOS DIVIDIDOS POR ZONAS}

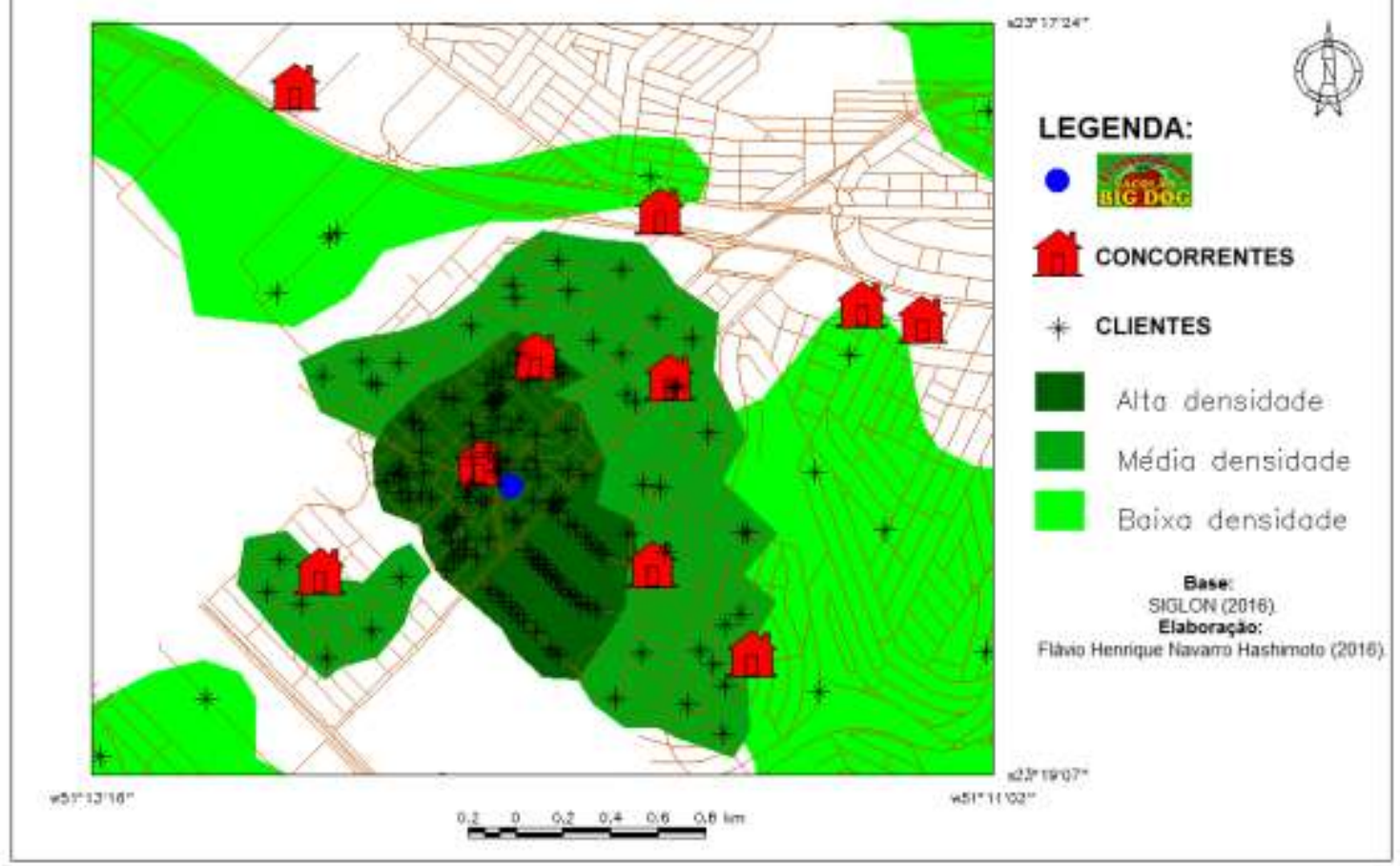

Fonte: Hashimoto (2016).

O critério utilizado para definir as densidades levou em consideração a proximidade do cliente à empresa. Quanto mais próximo ao supermercado, mais acessível o seu acesso e, consequentemente, um maior uso dos serviços realizados pelo Big Dog. Alinhado a esse critério, também foi considerado o relato dos entrevistados.

$\mathrm{Na}$ sequência, na Figura 6, é demonstrada no mapa a localização de todos os entrevistados na pesquisa. Dos 200 entrevistados, três não foram anotados no mapa, uma vez que um dos entrevistados residia no município de Centenário do Sul/PR, outro no município de Cambé/PR e o terceiro no Distrito de Irerê do município de Londrina/PR.

Neste mapa da Figura 6 se visualiza como a maior parte dos entrevistados reside na Região Oeste da área urbana de Londrina, contudo a empresa contém consumidores das regiões Norte, Sul e Leste. Além destas regiões, se identificou clientes residentes da área central de Londrina. Devido a essa informação, é possível considerar que o Supermercado Sacolão Big Dog consegue atrair consumidores de várias partes da área urbana de Londrina. 
Figura 6 - Localização de todos os clientes entrevistados na área urbana em Londrina-PR

\section{LOCALIZAÇÃO DE TODOS OS CLIENTES}

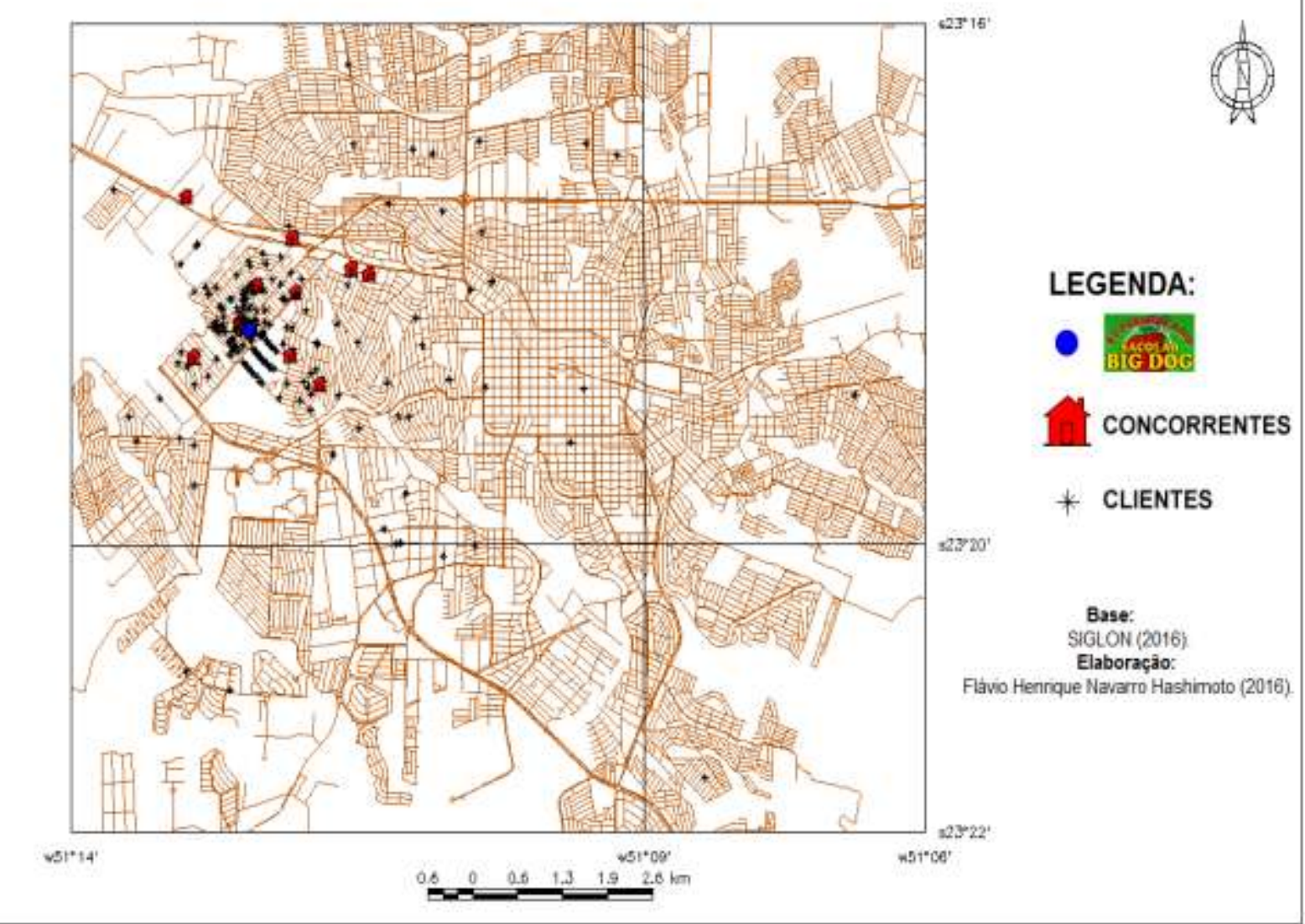

Fonte: Hashimoto (2016).

Já a Figura 7 se observa como se dá a densidade de consumidores da empresa em uma escala da área urbana da cidade. Assim como na Figura 5, foram utilizados os mesmos critérios para definir as densidades. Mesmo assim, se considerar que todas as regiões apresentam concorrentes dos mais diversos portes, o Supermercado Sacolão Big Dog consegue se tornar atrativo e atrair consumidores das mais diversas partes da cidade.

Já na Tabela 1 é informado o nível de satisfação por itens perguntados para os clientes entrevistados. O primeiro item avaliado são os preços dos produtos comercializados. Antes de discutir os dados deste primeiro item, é necessário destacar a crise financeira que o Brasil sofreu no ano de 2016, alinhado com a crise política que causaria o golpe/impeachment da então presidente Dilma Rousseff (PT). Devido a toda essa situação, é preciso considerar que os clientes podem ter sido influenciados na sua decisão ou não.

Ao todo, nesse primeiro item, 98 pessoas deram nota três para os preços, tendo como justificativa a sua situação financeira e o aumento que os produtos tiveram além do normal. 
O Geomarketing como Instrumento para a Pesquisa de Mercado: estudo de caso do Supermercado...

No entanto, 48 deram nota quatro e 39 deram nota cinco, demonstrando que mesmo na crise os preços continuaram em conta no Supermercado Sacolão Big Dog.

Figura 7 - Todos os consumidores divididos por zonas na área urbana em Londrina-PR

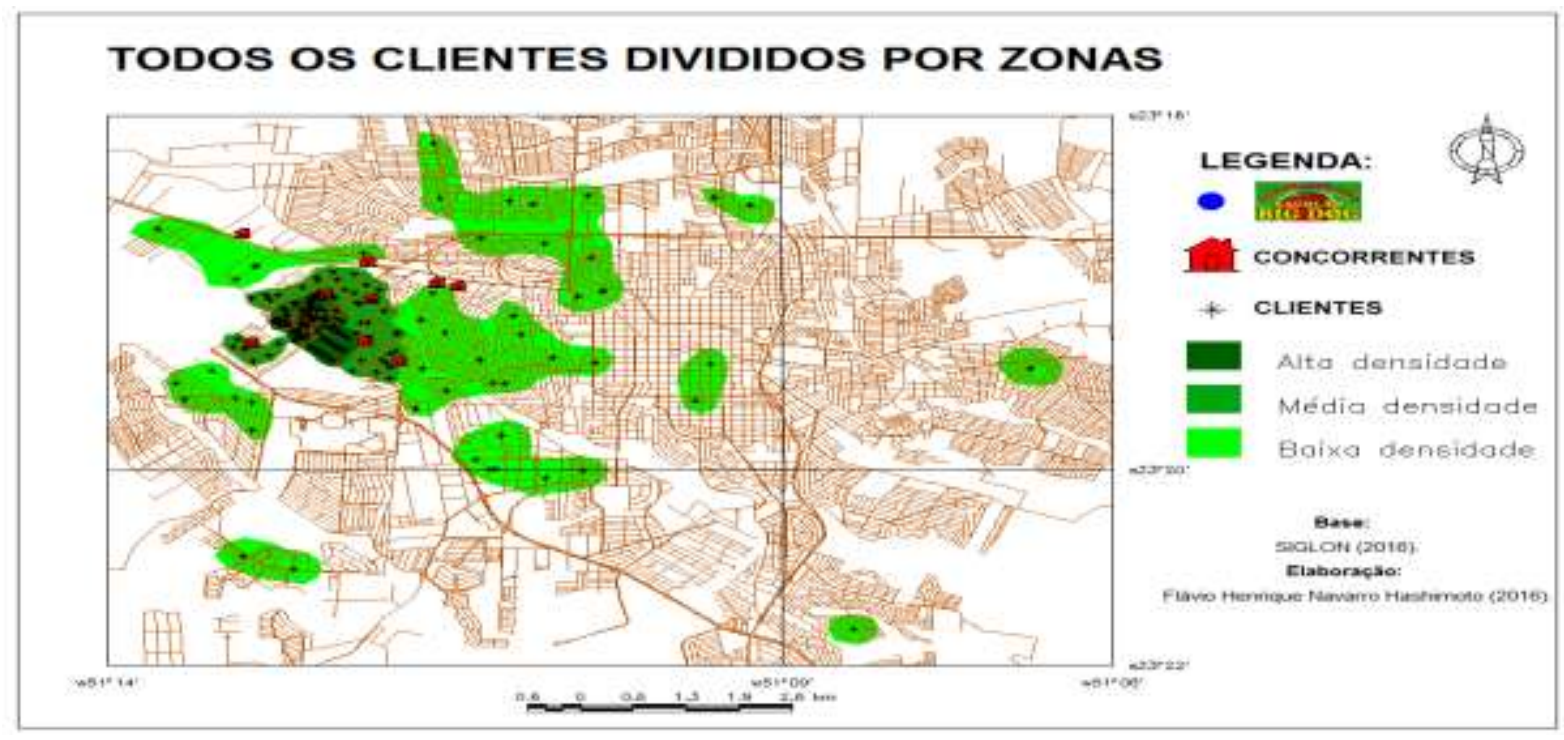

Fonte: Hashimoto (2016).

Tabela 1 - Nível de satisfação

\begin{tabular}{|c|c|c|c|c|c|c|c|}
\hline \multicolumn{8}{|c|}{ NOTAS } \\
\hline SEXO & ITENS & 1 & 2 & 3 & 4 & 5 & $\begin{array}{l}\text { Não Soube } \\
\text { Informar }\end{array}$ \\
\hline \multirow{8}{*}{$\begin{array}{l}\text { Feminino/ } \\
\text { Masculino }\end{array}$} & Preços & 3 & 12 & 98 & 48 & 39 & - \\
\hline & $\begin{array}{l}\text { Localização do } \\
\text { Supermercado }\end{array}$ & 2 & 3 & 19 & 58 & 118 & - \\
\hline & $\begin{array}{l}\text { Estrutura do } \\
\text { Supermercado }\end{array}$ & 8 & 36 & 62 & 47 & 47 & - \\
\hline & Atendimento & 2 & 7 & 20 & 67 & 104 & - \\
\hline & Qualidade da Mercadoria & - & 1 & 18 & 69 & 112 & - \\
\hline & $\begin{array}{l}\text { Diversidade de } \\
\text { Mercadoria }\end{array}$ & 2 & 12 & 50 & 59 & 77 & - \\
\hline & Espera no caixa & 2 & 15 & 62 & 60 & 61 & - \\
\hline & $\begin{array}{c}\text { Sanitários disponíveis } \\
\text { para clientes }\end{array}$ & 15 & 18 & 12 & 10 & 20 & 125 \\
\hline
\end{tabular}

Fonte: Hashimoto (2016).

No quesito localização, a nota cinco foi a mais dada, sendo que 118 entrevistados deram a nota máxima. A nota três foi dada por 19 entrevistados, nota dois por três entrevistados e nota um por dois entrevistados.

Devido a essa informação se constatou que o supermercado contém uma localização estratégica positiva. Outro ponto de valorização da localização se deve aos 
estabelecimentos comerciais próximos que não atrapalham, mas colaboram, já que se alguém necessitar de algo desses comércios podem também irem ao supermercado.

No item seguinte é questionada a estrutura do supermercado, que teve como maior a nota o três, dada por 62 pessoas. Essa nota intermediária algumas vezes se deve à estrutura interna do supermercado, no qual foram relatados alguns fatores, como: corredores pequenos e sem muito espaço de circulação livremente. Em seguida, a nota quatro e cinco receberam 47 votos. Na Figura 08 é possível conferir o porquê de a nota três ser a mais dada.

Figura 8 - Imagem interna do Supermercado Sacolão Big Dog

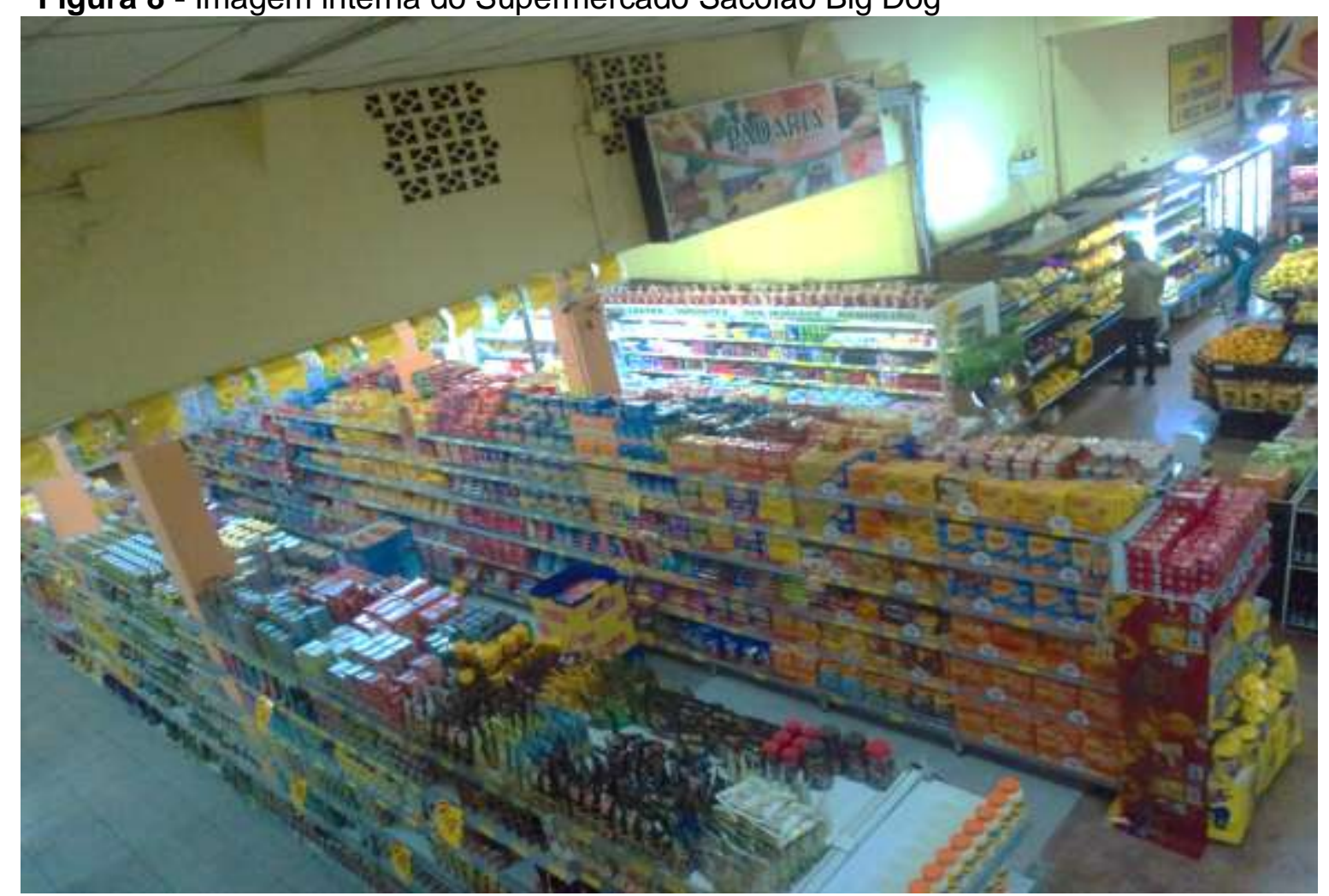

Fonte: Hashimoto (2016).

Em seguida, no item atendimento, a nota cinco novamente foi a mais indicada, sendo apontada por 104 entrevistados, seguido da nota quatro com 67 entrevistados. Isso demonstra o cuidado que o Big Dog tem pelos seus clientes reflete no ótimo atendimento. Os clientes, nos dias atuais, estão cada vez mais informados e exigentes (FERRARI, 2016) e as empresas precisam buscar sempre o melhor atendimento, uma vez que isso poderá refletir na fidelidade com a marca. O Supermercado Sacolão Big Dog vem conseguindo realizar esse objetivo, mesmo tendo tido relatos negativos, mas nada que seja tão crítico.

Sobre a qualidade das mercadorias, novamente a nota cinco foi a mais indicada, desta vez por 112 entrevistados, seguido da nota quatro apontada por 69 entrevistados. Essa 
indicação máxima se deve à qualidade dos produtos, principalmente do hortifrúti e carne, que receberam muitos elogios.

$\mathrm{Na}$ sequência foi perguntado sobre a diversidade de mercadorias, item esse que teve 77 entrevistados dando nota cinco e 59 notas quatro. Mesmo com boa avaliação nesse quesito, 50 entrevistados deram nota três, alegando a pouca oferta de marcas em alguns produtos.

Em seguida foi perguntado sobre a espera no caixa, fator esse que deve ser melhor analisado, pois 62 entrevistados deram nota três, nota intermediária. Em seguida há uma pequena diminuição na nota quatro e um aumento pequeno na nota cinco. Na Figura 9 é possível verificar como são os caixas do supermercado e o porquê dessa nota intermediária.

Figura 9 - Imagem dos caixas

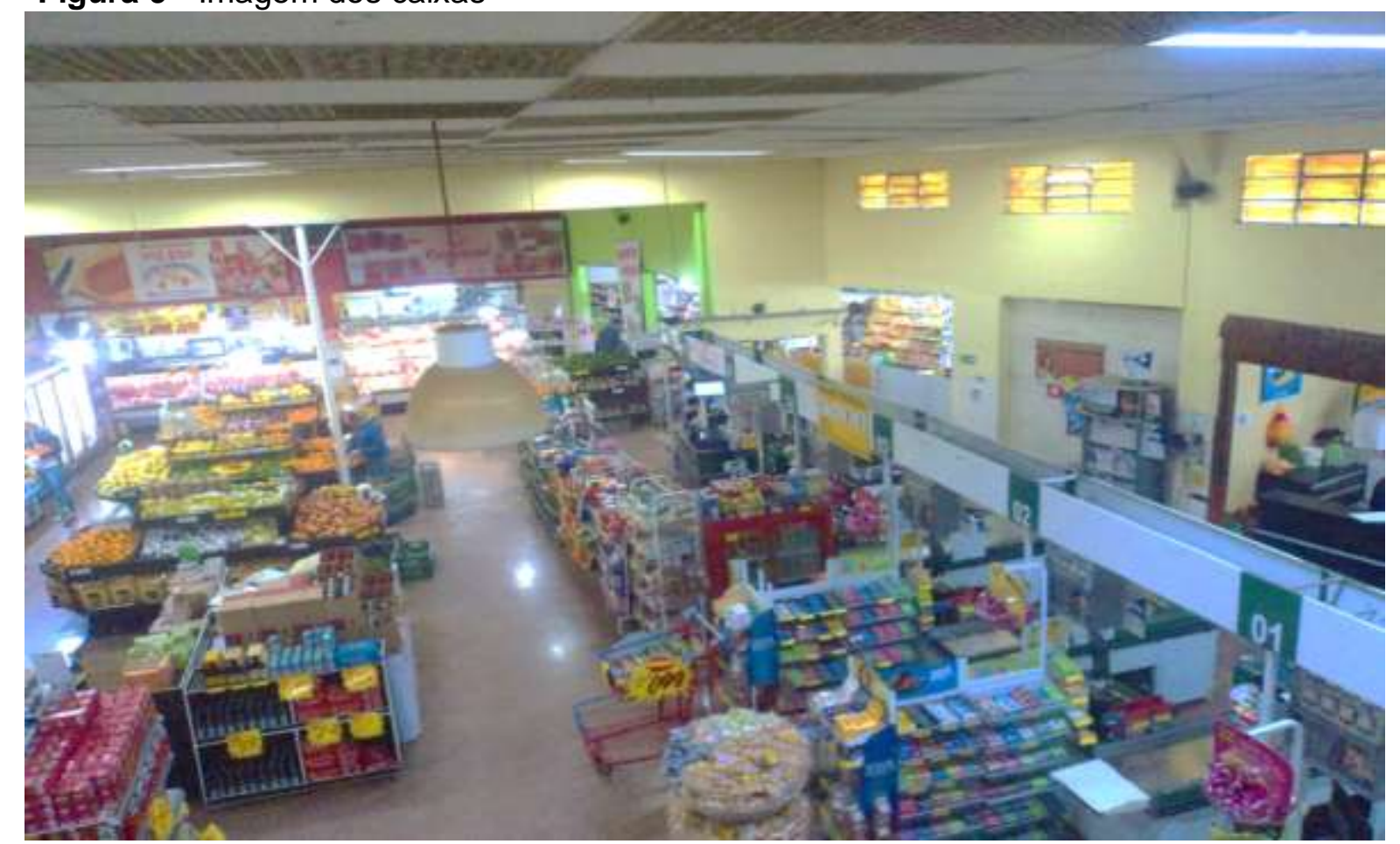

Fonte: Hashimoto (2016).

Mas, o mais preocupante se refere aos 125 entrevistados que disseram não saberem da existência de sanitários para clientes. Esse resultado não é positivo, uma vez que se o cliente necessitar utilizar o sanitário terá que ir para outro local e, em certas ocasiões, deixar de terminar a compra, resultando em um prejuízo financeiro para a empresa.

Nota-se na Figura 10 a não existência de informação sobre a existência de sanitários, além do mais o acesso apresentou ser dificultoso para os consumidores. Identificado essa situação e relatado para o proprietário da empresa, foi providenciada a melhoria do acesso e de identificação. Atualmente contém uma placa e o acesso se apresenta de livre circulação. 
Figura 10 - Imagem de acesso aos sanitários

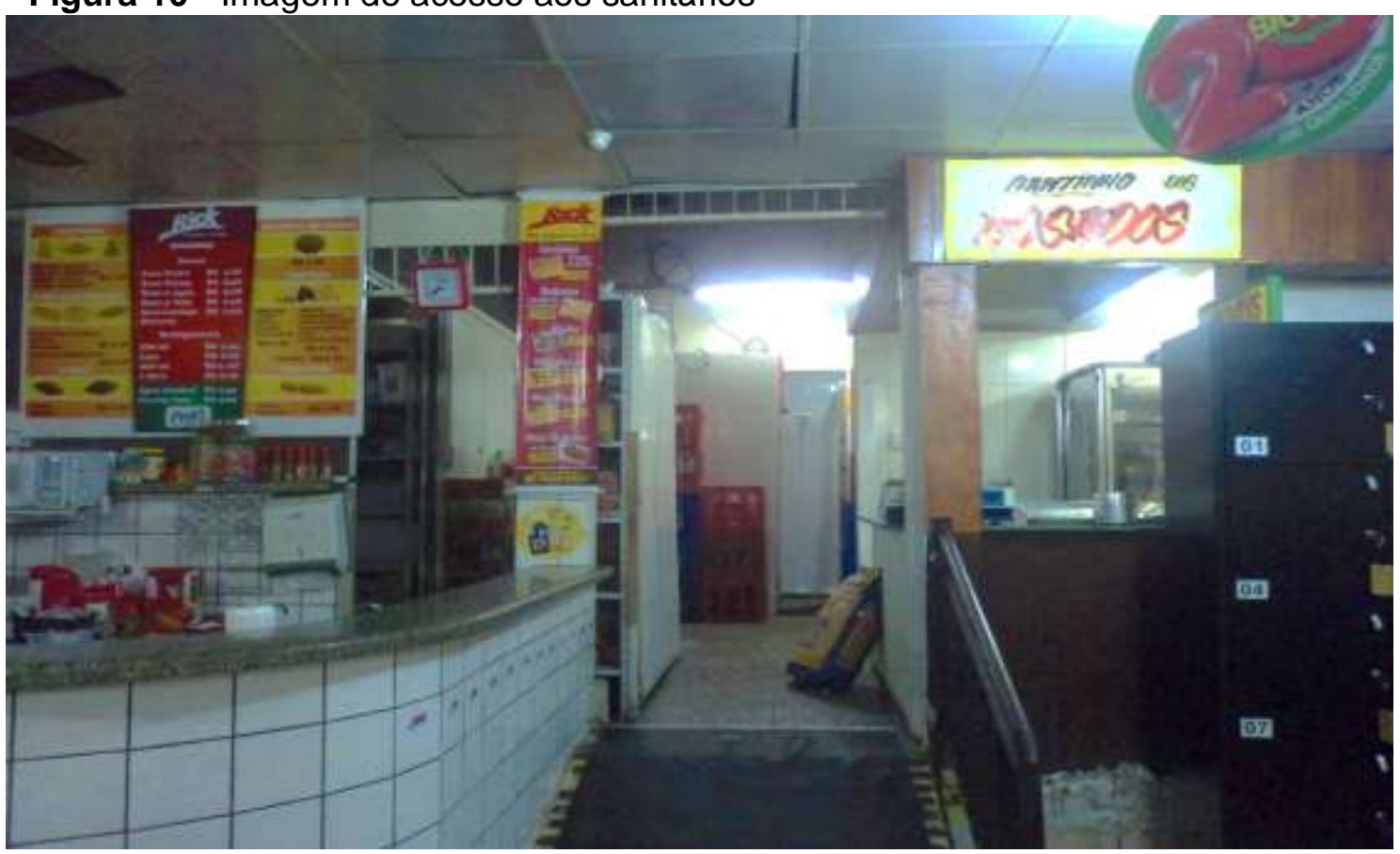

Fonte: Hashimoto (2016).

Por fim, após descobrir o que os clientes pensam sobre a empresa, foi possível buscar planejar estratégias mais precisas e que causem maior eficácia. Visando enfrentar o fator físico da empresa, foi então tomado a criação de iniciativas que pudessem atrair a clientela e, assim, mesmo a empresa não contendo uma estrutura física favorável, foi buscado demonstrar para os clientes que compensa ainda consumirem os produtos do Supermercado Sacolão Big Dog.

\section{CONCLUSÃO}

O presente estudo buscou, por meio do geomarketing, realizar uma análise da situação mercadológica de um supermercado de porte pequeno do município de LondrinaPR. O Supermercado Sacolão Big Dog foi o escolhido e mesmo que seja de porte pequeno, a empresa apresenta uma significativa presença, sendo um local que atrai clientes de várias regiões do município de Londrina e dos municípios próximos.

No entanto, é possível representar e demonstrar de fato essa presença do supermercado? Para isso, o geomarketing, área que busca compreender como se comporta o mercado por meio do geoprocessamento, foi utilizado como caminho para averiguar a situação mercadológica do Supermercado Sacolão Big Dog.

Constatou-se que o Supermercado Sacolão Big Dog, chamado de "Big Dog" pelos clientes mais frequentes, contém uma atuação espacial considerável e representativa. Mesmo tendo nas proximidades a presença de concorrentes, principalmente de 
concorrência de grande porte (que são os Super Muffato, mas que atualmente é o Max Atacadista e o Assaí Atacadista), faz com que as atuações dessas empresas não impactam negativamente, mas colabora, uma vez que esses supermercados de grande porte estão servindo de fonte de conhecimento, segundo relato do proprietário.

Por meio do geomarketing se constatou que o Supermercado Sacolão Big Dog atrai consumidores das quatro regiões urbanas de Londrina e da área central. Além disso, foi identificado que consumidores de outros municípios preferem consumirem os produtos do Supermercado Sacolão Big Dog do que os produtos dos supermercados próximos de sua residência. Mesmo que a empresa tenha fatores da estrutura física não favoráveis, busca alternativas, como a questão da qualidade da mercadoria e do atendimento, para se sobrepor.

Assim, é possível dizer que o Supermercado Sacolão Big Dog consegue se fazer presente em um setor competitivo, mesmo com as suas limitações. Além do mais, se observa que essa empresa apresenta um potencial de crescimento, desde que sempre busque prezar no que atrai os consumidores, que é o atendimento e a qualidade da mercadoria de hortifrúti e de carne.

\section{REFERÊNCIAS}

ASSUREL. Quem somos: porque os supermercados da rede Assurel podem vender mais barato. Disponível em: <http://www.assurel.com.br/site/quem-somos.php>. Acesso em: 2 jul. 2018.

CANOVA, G. R. N. Geomarketing como ferramenta de análise do mercado imobiliário: estudo de caso. Florianópolis (SC). 2007. Dissertação (Mestrado em Engenharia Civil) Universidade Federal de Santa Catarina, Florianópolis.

CAVION, R. Geomarketing para a gestão territorial: Mapeamento de ameaças e oportunidades. 2008. Dissertação (Mestrado em Engenharia Civil) - Universidade Federal de Santa Catarina, Florianópolis.

DASCALU, O.; ALBULESCU, S. Geomarketing Implementation in the Romanian Automotive Distribution Industry. In: CONFERENCE OF INFORMATICS AND MANAGEMENT SCIENSE, 2., 2014, Zilina, SK. Anais... Zilina: Zilinska Universitá, 2014. p. 49-53.

FERRARI, W. A importância do atendimento personalizado. 2016. Disponível em: $<$ http://www.varejista.com.br/artigos/atendimento-ao-cliente/988/a-importancia-doatendimento-personalizado >. Acesso em: 10 set. 2018.

FURLAN, A. A. Geoprocessamento: estudos de geomarketing e as possibilidades de sua aplicação no planejamento do desenvolvimento socioeconômico. Revista GEOUSP: Espaço e Tempo, São Paulo, n. 29, p. 97-105, 2011. Disponível em: <www.revistas.usp.br/geousp/article/view/74208/77851 >. Acesso em: 15 ago. 2018.

GOOGLE. Google Earth. Disponível em: <https://www.google.com/earth/>. Acesso em: 17 out. 2018. 
HASHIMOTO, F. H. N. O geomarketing na pesquisa de mercado: estudo de caso do Supermercado Sacolão Big Dog localizado em Londrina-PR. 2016. Trabalho de Conclusão de Curso (Graduação em Geografia) - Universidade Estadual de Londrina, Londrina.

INSTITUTO NACIONAL DE PESQUISAS ESPACIAIS - INPE. Divisão de Processamento de Imagens - DPI. O que é o SPRING? 2017. Disponível em:

<http://www.dpi.inpe.br/spring/portugues/index.html>. Acesso em: 10 set. 2018.

LONDRINA. Prefeitura Municipal. Londrina em dados: 2017 (Ano base 2016): aspectos demográficos. 2017a. Disponível em:

$<$ http://www.londrina.pr.gov.br/index.php?option=com_content\&view=article\&id=543\&ltemid= 558\&li_LONDRINA_mitstart=4\&limitstart=3>. Acesso em: 15 ago. 2018.

LONDRINA. Prefeitura Municipal. Londrina em dados: 2017 (Ano base 2016): aspectos socioeconômicos. 2017b. Disponível em:

$<$ http://www.londrina.pr.gov.br/index.php?option=com_content\&view=article\&id=543\&ltemid= 558\&li_LONDRINA_mitstart=4\&limitstart=4>. Acesso em: 15 ago. 2018.

LONDRINA. Prefeitura Municipal. Sistema de Informação Geográfica de Londrina: SIGLON. Downloads. 2017c. Disponível em:

<http://www.londrina.pr.gov.br/index.php?option=com_content\&view=article\&id=20114\&ltemi $\mathrm{d}=1988>$. Acesso em: 17 out. 2018.

MACHADO, C. C.; FRANCISCO, E. de R.; RIBEIRO, J. G. P. A Geodemografia e o geomarketing na identificação de mercados potenciais. Demographicas, São Paulo, 2006. Disponível em: <http://www.abep.org.br/publicacoes/index.php/series/article/view/67/65>. Acesso em: 17 out. 2018.

SEABRA, A. L. de Castro. Geomarketing: estudo de áreas de influência de um restaurante de healthy food em Natal-RN. 2014. Trabalho de Conclusão de Curso (Graduação em Administração) - Universidade Federal do Rio Grande do Norte, Natal.

SUPERMERCADO BIG DOG. Conheça o Supermercado Big Dog. 2018. Disponível em: <http://www.superbigdog.com.br/supermercado-bigdog.html>. Acceso em: 2 jun. 2018.

YRIGOYEN, C. C. El geomarketing y la distribución comercial. Investigación y Marketing, Madrid, n. 79, p. 6-13, 2003. Disponível em: <http://old.aedemo.es/socios/revista79/ad-7901.pdf>. Acesso em: 25 ago. 2015.

Recebido: abril de 2018. Aceito: outubro de 2018. 